\title{
ANELASTICITY BENEATH THE AEGEAN INFERRED FROM RAYLEIGH WAVE ATTENUATION
}

\author{
Kassaras I. ${ }^{1}$, Louis F. ${ }^{1}$, Magganas A. ${ }^{2}$, Makropoulos K. ${ }^{1}$, and Kaviris G. ${ }^{1}$ \\ ${ }^{1}$ National and Kapodistrian University of Athens, Faculty of Geology and Geoenvironment, \\ Department of Geophysics-Geothermics,, Panepistimioupolis, Zografou, Athens 15784, \\ kassaras@geol.uoa.gr,flouis@geol.uoa.gr,kmacrop@geol.uoa.gr,gkaviris@geol.uoa.gr \\ ${ }^{2}$ National and Kapodistrian University of Athens, Faculty of Geology and Geoenvironment, \\ Department of Petrology-Mineralogy, Panepistimioupolis, Zografou, Athens 15784, \\ amagganas@geol.uoa.gr
}

\begin{abstract}
Anelasticity of the Earth crucially affects the propagation of seismic waves especially, in the long period range. However, even though the elastic properties of the Aegean deep lithosphere and upper mantle have been thoroughly investigated, their quantitative anelastic properties that influence the long period wavefield are still largely unknown. This work is towards contributing to the better knowledge of the deep structure of the Aegean by introducing experimental anelastic parameters via the study of long period Rayleigh waves attenuation.

For this scope, fundamental mode attenuation coefficients $\left(\gamma_{R}\right)$ have been obtained for different two-station great-circle paths across the Aegean. The data used were provided by a broadband array installed in the area for 6 months in 1997. More than 1100 seismograms were analyzed in the 10-100 s range to obtain 17 sets of path average $\gamma_{R}(T)$ functions. The attenuation coefficients are in the range $2.5 \times 10^{-3}$ $-0.15 \times 10^{-3} \mathrm{~km}^{-1}$ and correlate sufficiently with both experimental measurements in active tectonic regions elsewhere and synthetics generated with the use of an attenuation reference model inferred from other sources. By applying a stochastic uncoupled causal inversion method an average joint $Q_{\beta}{ }^{-1}$ and shear velocity model representative of the under study area was obtained. Furthermore, path average $\gamma_{R}(T)$ functions were combined in a continuous regionalization tomographic scheme to obtain local $\gamma_{R}(T)$ and tomograms were constructed in the range 10-60 s. The most prominent feature in the tomograms is a high attenuation region in the central and north Aegean. This region is located south of the North Anatolian Trough and correlates well with a low shear velocity zone inferred from surface wave phase velocities. Moreover, it is associated with observed intense extensional deformation rates, mantle olivine anisotropy, recent volcanism and high heat flow.
\end{abstract}

Key words: Causal Inversion, Tomography, Continuous Regionalization.

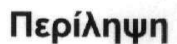

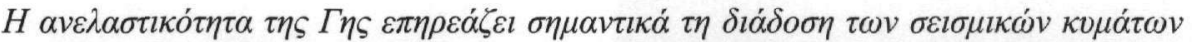

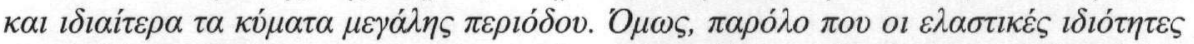

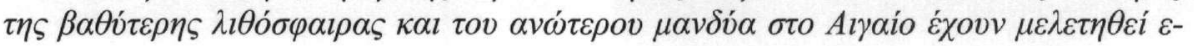




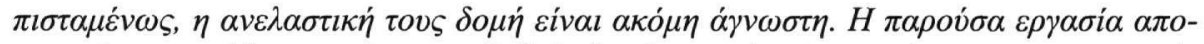

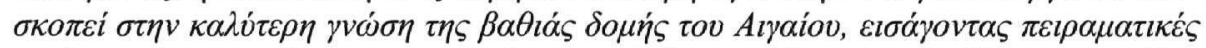

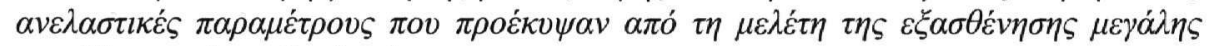

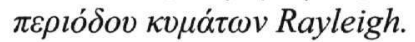

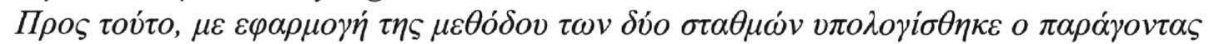

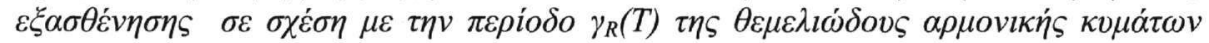

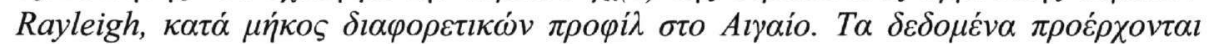

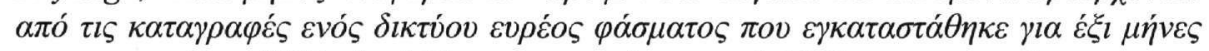

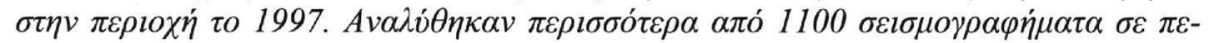

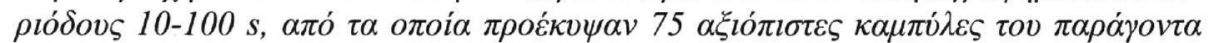

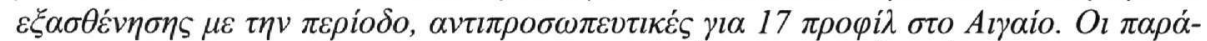

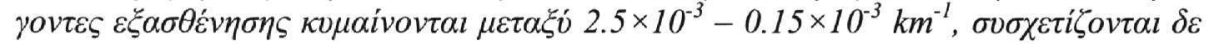

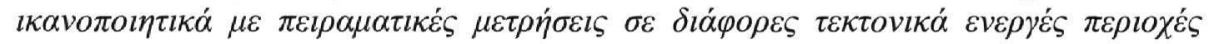

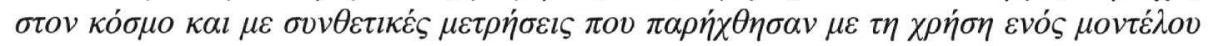

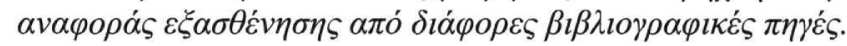

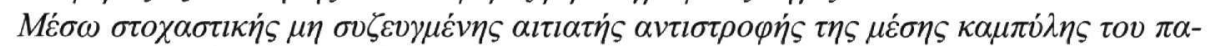

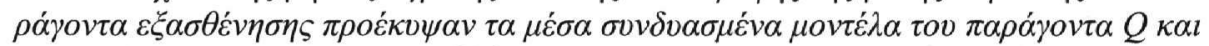

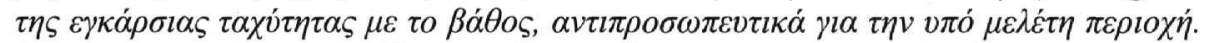

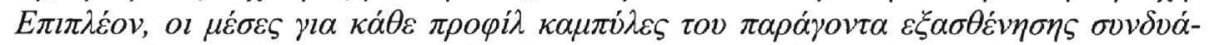

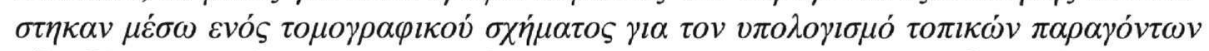

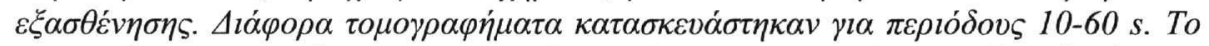

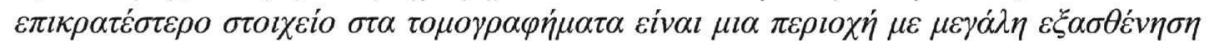

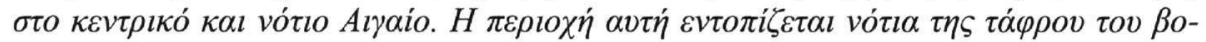

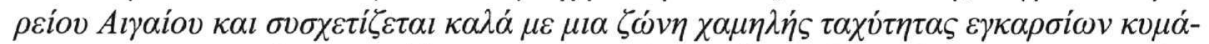

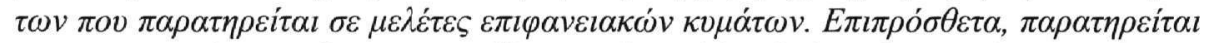

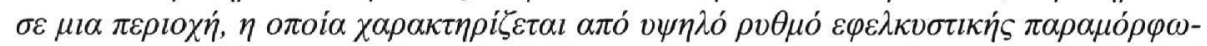

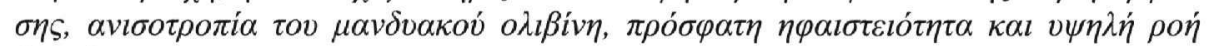
$\theta \varepsilon \rho \mu o ́ \tau \eta \tau \alpha \varsigma$.

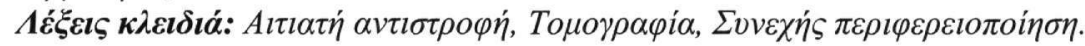

\section{Introduction}

Reflection and transmission of seismic waves at discrete interfaces reduce their amplitudes. Four other processes also reduce the wave amplitudes: geometrical spreading, scattering, multipathing, anelasticity. The first three are elastic processes, in which the energy in the propagating wave field is conserved. In contrast, anelasticity, also called intrinsic attenuation, involves conversion of seismic energy to heat. Seismic velocities depend nearly linearly upon temperature, whereas intrinsic attenuation depends exponentially on temperature. It is, hence, important to study attenuation since it can provide information on temperature, fluid content, phase change, and density of solid-state defects in the crust and mantle, phenomena that are not easily studied using only seismic wave velocities.

The Aegean Sea is a rapidly deforming region. Its deformation rate has been estimated $>4 \mathrm{~cm} . \mathrm{yr}^{-1}$ (McClusky et al. 2000). This high rate is due to the westward motion of the Anatolian plate and the subduction of the eastern Mediterranean lithosphere beneath the Aegean. The Aegean back-arc area is mainly deforming by normal faulting combined with strike-slip motions. The back-arc area is also characterized by high heat flow, $200 \%$ higher when compared to the eastern Mediterranean (Jongsma 1974).

Several $Q$ studies have been carried out in Greece. Papazachos and Comninakis (1971) were the first to point out the high attenuation of seismic rays that travel through the southern Aegean Sea. Shear and Coda waves for high frequencies have been also used to study $Q_{\mathrm{b}}$ and $Q_{\mathrm{c}}$ in Greece inferring a strong frequency dependence (e.g. Kovachev et al. 1991, Tselentis 1993, Hatzidimitriou et al. 1993, Polatidis et al. 2003). 
Seismic surface waves have been widely used to study the shear-wave velocity distribution in the Aegean (most recently Bourova et al. 2005, Kassaras et al. 2005, Karagianni et al. 2005). However, evident is the lack of surface wave attenuation studies, which, in contradiction to body or coda waves can provide information on the depth dependence of $Q$, inferring resources to understand the material and physical conditions in the lithosphere and upper mantle. Toward this direction, we computed attenuation coefficients of fundamental mode Rayleigh waves in the 10-100 s period range. 17 path average attenuation curves were obtained using the two-station method and were furthermore inverted via a continuous regionalization tomographic scheme to obtain local attenuation coefficients. Thereafter, a causal-uncoupled inversion of the average phase velocity and attenuation curve lead us to obtain a joint $Q_{\beta}{ }^{-1}$ and shear velocity model over the entire region.

\section{Data and method}

\subsection{Data}

The data of this study comprise teleseismic waveforms recorded during a 6 month large scale experiment conducted in Greece in 1997. A brief description of the experiment can be found at other sources (e.g., Hatzfeld et al. 2001). In this study, recordings from 12 stations, equipped with 60 and $100 \mathrm{~s}$ sensors were used (Fig. 1).

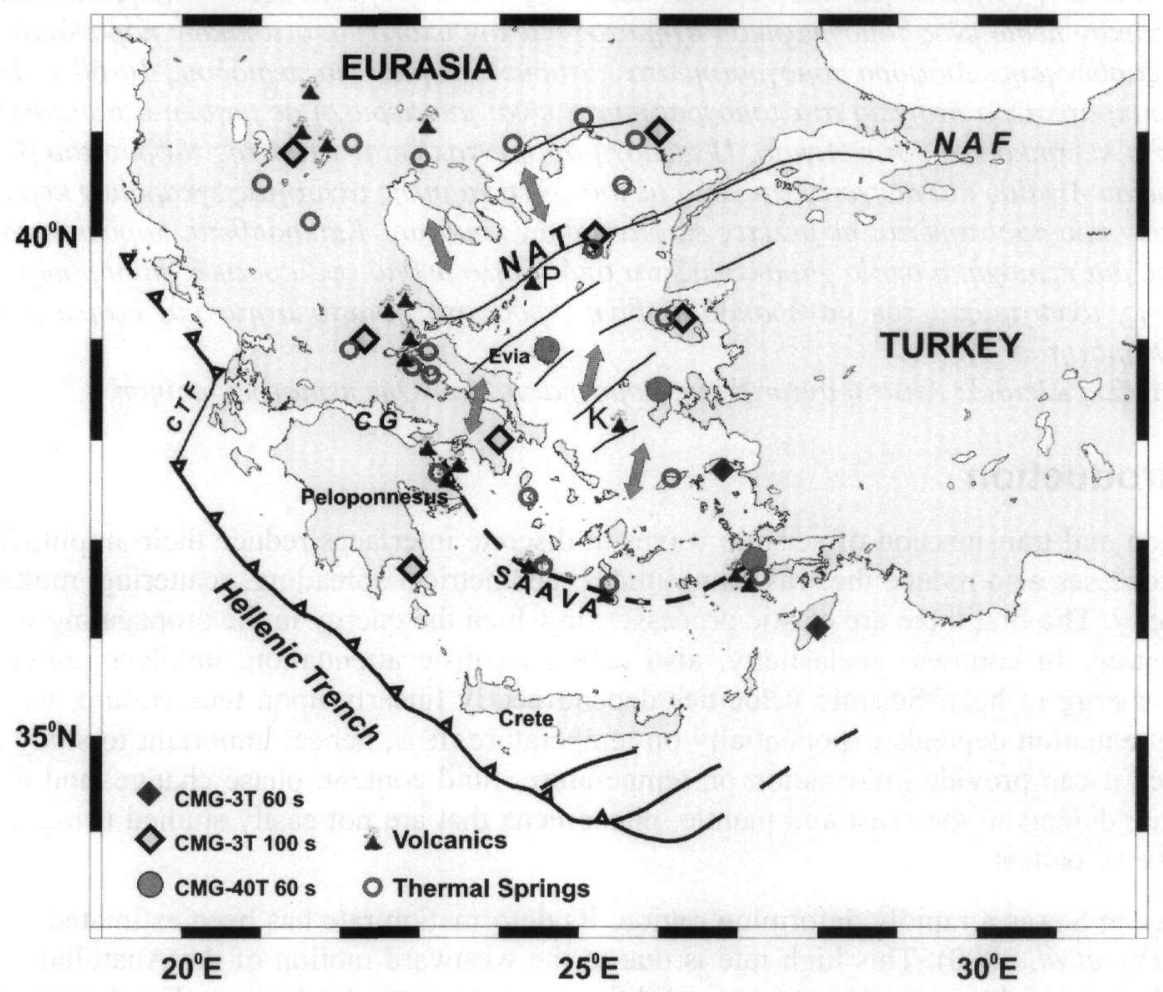

Figure 1 - Map showing the location of the stations used in the present study, main active tectonic features of the Aegean after Armijo et al. (1999), Pliocene to Recent volcanic centers and main thermal springs. Abbreviations for geographical names: $\mathrm{CG}=$ Corinth Gulf; NAT

$=$ North Aegean Trough; NAF $=$ North Anatolian Fault; SAAVA $=$ South Aegean Active

Volcanic Arc; CTF = Cephalonia Transform Fault; $\mathbf{P}=$ Psathoura; $\mathrm{K}=$ Kalogeri

Out of all the recorded earthquakes of epicentral distance larger than $30^{\circ}$, we analyzed waveforms generated by 386 events showing a good-quality signal at most of the stations. In the study, all events lay within $3^{\circ}$ in azimuth from great-circle paths between the two recording stations. Be- 
cause of the different sensors and recorders, the data were corrected for the instrument response. The mean ground motion was also removed from the records and bandpass filtering was applied.

\subsection{Method}

\subsubsection{Attenuation coefficient measurements}

The Multiple Filter Technique (MFT) (Herrmann 1973) was utilized for the identification of the fundamental Rayleigh waves and to extract group velocities and spectral amplitudes. About 1000 seismograms were analyzed and spectral amplitudes of the fundamental mode vertical components of Rayleigh waves were obtained for 510 pairs of stations. After rejecting largely erroneous data, the two-station method was applied for 330 pairs of stations to obtain the attenuation coefficients in the period range 10-100 s. According to the well-known two-station method, the averaged coefficient for the $k_{t h}$ path and period T between stations $s_{i}$ and $s_{j}$ is given by:

\section{Equation 1 - Formula for interstation $\gamma$ calculation}

$\gamma_{k}(T)=D_{k}^{-1} \ln \frac{A_{s i}(T)}{A_{s j}(T)}$

where $D_{k}$ is the distance between stations and $A_{s i}(T)$ and $A_{s j}(T)$ are spectral amplitudes of the fundamental mode, recorded at stations $s_{i}$ and $s_{j}$. The spectral amplitudes were corrected for the geometrical spreading effect.

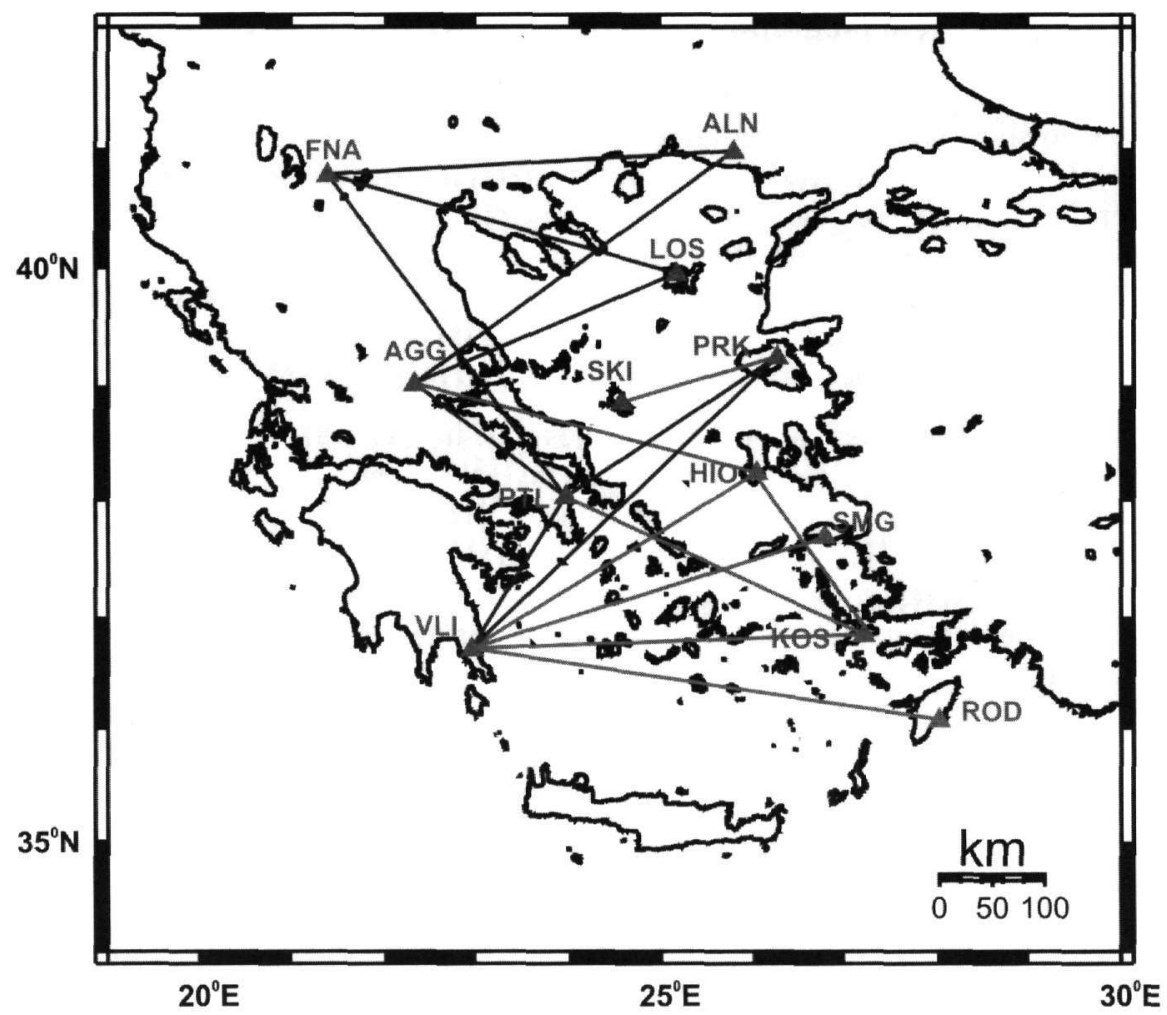

Figure 2 - Paths for which attenuation coefficient measurements were obtained

Using the two-station method, the unknown radiation pattern is removed when computing the quotient (Equation 1). Attenuation data have to be carefully verified especially when the area of interest is subject to lateral heterogeneities due to effects of focusing, defocusing, departures from the great-circle path and multipathing, which impact the quality of the empirical attenuation coeffi- 
cient. Other relevant error aspects are the site effect and the instrumental response of the seismometers if they are not correctly calibrated. To minimize those effects two tasks were performed. Firstly, we employed the seismograms used by Kassaras et al. (2005), who performed a strict seismogram selection procedure when working with phase velocities computed by the two-station method. For those selected seismograms we computed the quotient of Equation 1. Secondly, we conducted a synthetic experiment adequately parameterized for our study area. By utilizing an average 1-D shear velocity model derived for the region (Kassaras et al. 2005) and perturbing $Q_{\beta}$ between 10-100 we calculated the theoretical quotients of Equation 1 for various interstation distances, relevant to the lengths of our paths. Considering the results of the two procedures we set the tolerance range for our measurements. Furthermore, to control the errors for each individual path, we tried to collect as many events for each station pair as possible, adopting only similar observations, reducing thus the standard deviations of the mean values. Given that short interstation distances can cause problems when using the two-station method, results for the station pairs with shorter interstation distances were compared with those with longer interstation distances, and were also compared with the average values to examine the usability of the data.

As expected, given the strong impact of the above described effects, the largest part of the analyzed dataset exceeded the tolerance range and was consequently rejected. In conclusion, we adopted 75 interstation attenuation curves as representative of 17 paths across the Aegean (Fig. 2) and calculated the average value and the corresponding standard deviation of $\gamma_{R}$ for each period and each path. For the single period measurements, a value of $0.5 \times 10^{-3} \mathrm{~km}^{-1}$ was chosen as a conservative error estimate.

\subsubsection{Uncoupled causal inversion}

In a previous surface wave study in the Aegean (Kassaras et al. 2005), path average Rayleigh wave phase velocities have been inverted to obtain 1-D shear velocity models with depth. However, phase velocities are not independent from the anelastic structure and vice versa. In this study, average over the entire region phase velocities were employed together with the obtained average attenuation coefficients into a stochastic uncoupled causal inversion scheme (Herrmann 1991), in order to obtain joint average $Q_{\beta}{ }^{-1}$ and shear velocity model with depth, representative for the Aegean region. The misfit between the uncausal and causal shear velocities should give insight about the average material and physical conditions in the Aegean deep lithosphere and upper mantle.

The average over the entire region phase velocities together with the average attenuation coefficients were employed into two iterative stochastic inversion schemes; an uncausal and an uncoupled-causal. A slightly modified shear velocity model derived by Kassaras et al. (2005) was considered as a starting model (Table 1). Given the lack of relative information in the area, after several tests, a fixed $Q_{\mathrm{b}}$ value of 40 was used over the entire depth range $0-200 \mathrm{~km}$. In the uncausal scheme, in order to obtain the uncontaminated elastic-anelastic structure, iterations were performed independently from each other until a minimum misfit between empirical and theoretical values was achieved. In the uncoupled-causal procedure, in order to obtain the best possible structural model, each of the iterations was performed in two steps. Firstly, leaving unchanged the elastic part of the model and improving the anelastic part. Secondly, using the improved anelastic part, a new approach to a better elastic model was obtained. The entire process was repeated until again a minimum misfit between empirical and theoretical values was achieved. Figure 3 depicts the $Q_{\beta}{ }^{-1}$ and shear velocity models derived by ignoring and including causality effects. 

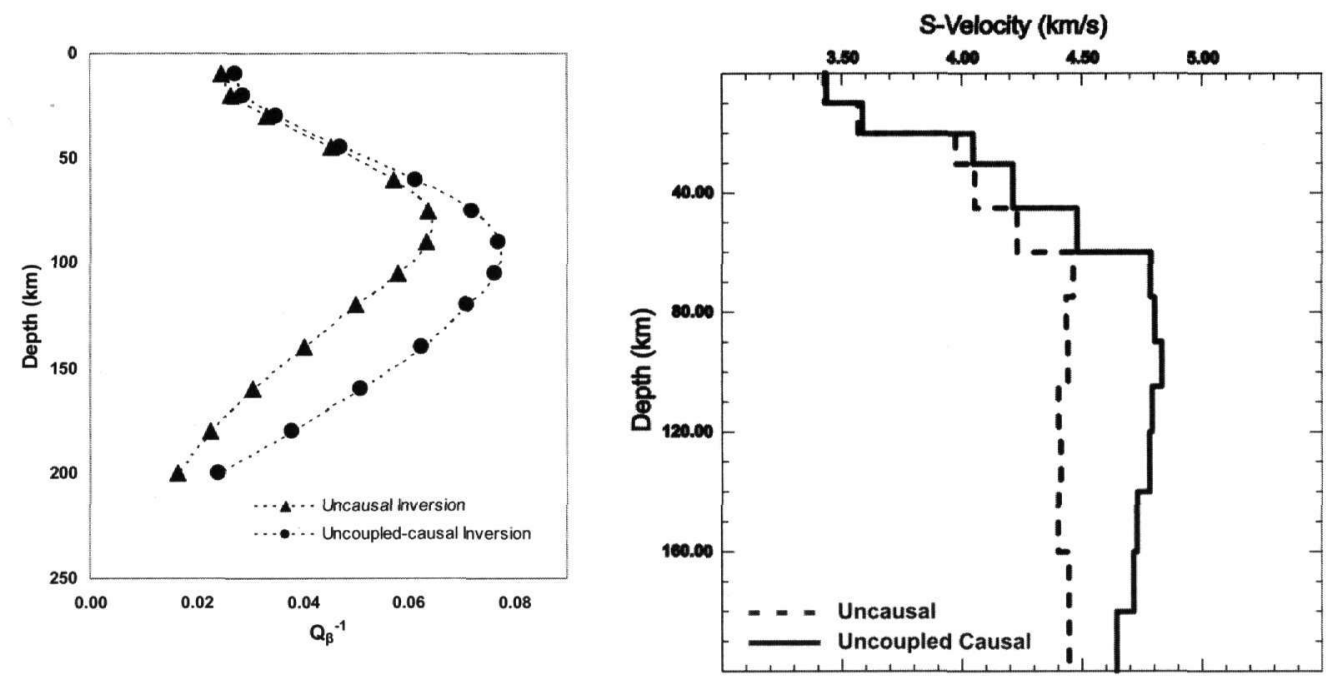

Figure 3 - Average $Q \beta^{-1}$ (left) and shear velocity (right) models deduced from uncausal and uncoupled-causal stochastic inversion

Table 1 - Summary of the results of the uncausal and uncoupled-causal stochastic inversion for the average elastic-anelastic structure of the Aegean region

\begin{tabular}{cccccccc} 
Depth & $\begin{array}{c}\text { Starting } \\
\text { Vs }\end{array}$ & \multicolumn{2}{c}{ Uncausal Inversion } & \multicolumn{3}{c}{ Inversion } \\
$(\mathrm{km})$ & $(\mathrm{km} / \mathrm{s})$ & $(\mathrm{km} / \mathrm{s})$ & $\begin{array}{c}\boldsymbol{Q}_{\boldsymbol{\beta}}{ }^{-1} \\
\left(\times 10^{-2}\right)\end{array}$ & $\boldsymbol{Q}_{\boldsymbol{\beta}}$ & $\begin{array}{c}\mathbf{V} \mathbf{k} / \mathrm{s}) \\
\boldsymbol{Q}_{\boldsymbol{\beta}}^{-1}\end{array}$ & $\left(\times 10^{-2}\right)$ & $\boldsymbol{Q}_{\boldsymbol{\beta}}$ \\
10 & 3.43 & 3.37 & 2.47 & 40 & 3.43 & 2.75 & 36 \\
20 & 3.57 & 3.51 & 2.65 & 38 & 3.58 & 2.88 & 35 \\
30 & 3.97 & 3.93 & 3.34 & 30 & 4.05 & 3.50 & 29 \\
45 & 4.05 & 4.02 & 4.54 & 22 & 4.21 & 4.71 & 21 \\
60 & 4.23 & 4.22 & 5.72 & 17 & 4.48 & 6.15 & 16 \\
75 & 4.46 & 4.46 & 6.37 & 16 & 4.78 & 7.19 & 14 \\
90 & 4.43 & 4.44 & 6.35 & 16 & 4.80 & 7.71 & 13 \\
105 & 4.44 & 4.44 & 5.82 & 17 & 4.83 & 7.64 & 13 \\
120 & 4.40 & 4.40 & 5.02 & 20 & 4.79 & 7.12 & 14 \\
140 & 4.41 & 4.41 & 4.03 & 25 & 4.78 & 6.25 & 16 \\
160 & 4.40 & 4.40 & 3.07 & 33 & 4.73 & 5.10 & 20 \\
180 & 4.45 & 4.44 & 2.26 & 44 & 4.71 & 3.80 & 26 \\
200 & 4.45 & 4.44 & 1.64 & 61 & 4.64 & 2.43 & 41
\end{tabular}

As expected, elastic models derived without considering causal effects, especially for layers deeper than $20 \mathrm{~km}$, are characterized by shear velocities lower than those obtained taking into account causal effects. The anelastic structures manifest a quite similar pattern, with the misfit between the two procedures been larger deeper than $60 \mathrm{~km}$. Average $\mathrm{Q} \beta$ values at depths from 0 to $200 \mathrm{~km}$ range between $29 \pm 13$ and $23 \pm 10$ for the non-causal and uncoupled-causal inversion respectively. In Table 1 we summarize the results of the inversion for the average elastic-anelastic structure of the study area. 


\subsubsection{Continuous regionalization of path-average attenuation measurements}

Continuous regionalization, a great circle approximation inversion scheme, was used to extract local attenuation coefficients from path-average attenuation data. The method consists of a continuous formulation of the inverse problem and the least-square criterion. The algorithm used was developed by Debayle and Sambridge (2004) and it is an optimized version of the Montagner (1986) approach for continuous regionalization of surface wave path-average measurements.

In the continuous regionalization algorithm, the lateral smoothness of the inverted model is obtained by assuming an a priori Gaussian correlation between neighbouring points with a specified scale length $L_{c o r r}$ and a scale factor $\sigma(r)$. The horizontal correlation length $\left(L_{c o r r}\right)$ is a spatial filter that constrains the lateral smoothness of the model. After some tests and regarding the path coverage of the area and the wavelengths used, $L_{c o r r}$ was chosen equal to $150 \mathrm{~km}$. The a priori standard deviation $\sigma(r)$ controls the amplitude of the perturbation allowed in the process. It was taken equal to $0.5 \times 10^{-3} \mathrm{~km}^{-1}$ according to a conservative $\gamma_{\mathrm{R}}$ error estimate.

The 17 path average attenuation coefficient curves obtained were combined over a $1 \times 1$ degree grid into a 3-D model for the lateral variations of attenuation using the continuous regionalization algorithm. The period range of the computed tomograms was restricted between 10 and $60 \mathrm{~s}$, since the poor path coverage beyond $60 \mathrm{~s}$ ( 8 paths) did not allow for efficient results.

\section{Results and discussion}

The attenuation model presented in this study was obtained from an inversion with $L_{\text {corr }}=150 \mathrm{~km}$, $\sigma(r)=0.5 \times 10^{-3} \mathrm{~km}^{-1}$. The a priori error $\sigma(r)$ defines to what extent the final model can vary from the reference one. Considering that the a priori initial model is a reference model for the region, this value is relatively large and should allow all realistic attenuation variations. Variation of $L_{c o r r}$ values does not affect the results, with respect to the conclusions we can draw.

Attenuation coefficient maps are shown for 6 periods varying from 10 to $60 \mathrm{~s} \mathrm{(Fig.} \mathrm{4).} \mathrm{Attenuation}$ variations are relative to the average attenuation coefficient at each period. The vertical distribution of the attenuation model, taking in account typical Rayleigh wave attenuation sensitivity kernels should be between $\sim 20-120 \mathrm{~km}$. Our observations for the period range $10-60 \mathrm{~s}$ can be summarized as follows:

The pattern of lateral attenuation perturbations is consistent with major shear velocity anomalies (Papazachos and Nolet 1997, Tiberi et al. 2000, Marone et al. 2004, Bourova et al. 2005).The main features of our model are the low attenuation anomaly in south Aegean and east Peloponnesus, associated with the African slab and the attenuation contrast between continental Greece and the central and north Aegean Sea. The most prominent feature of the model is a high attenuation area in central and north Aegean. Pleistocene to recent trachyandesitic volcanism and high heat flow, as expressed by hot springs in Central Greece (Thessaly and N. Evoicos Gulf), can be the result of mantle originated magmas differentiated during their ascent through the relatively thin crust of the area (Innocenti et al. 1979, Pe-Piper and Piper 2002, Makris et al. 2001). The southwestwards NAF propagation during the last $5 \mathrm{Ma}$, which has reached the eastern continental coast of Central Greece, may also be of significant importance to both volcanism and high attenuation mantle zone in this particular location. The presence of this zone could be attributed to several reasons, including melting in the asthenosphere and distributed deformation. Indeed, the NAF in the area and the associated intense north-south extension caused rapid tectonic instability in the area expressed in both mantle and crustal levels. NE-SW mantle olivine anisotropy (Hatzfeld et al. 2001) and extension in about the same direction suggest upper mantle deformation or flow. Magmatic mantle processes are manifested in the small volcanic islets of Psathura and Kalogeri of Northern and Central Aegean, respectively. They consist of sodic basalts derived from Oceanic Island Basalt (OIB) asthenospheric mantle source similar in geochemical character to 


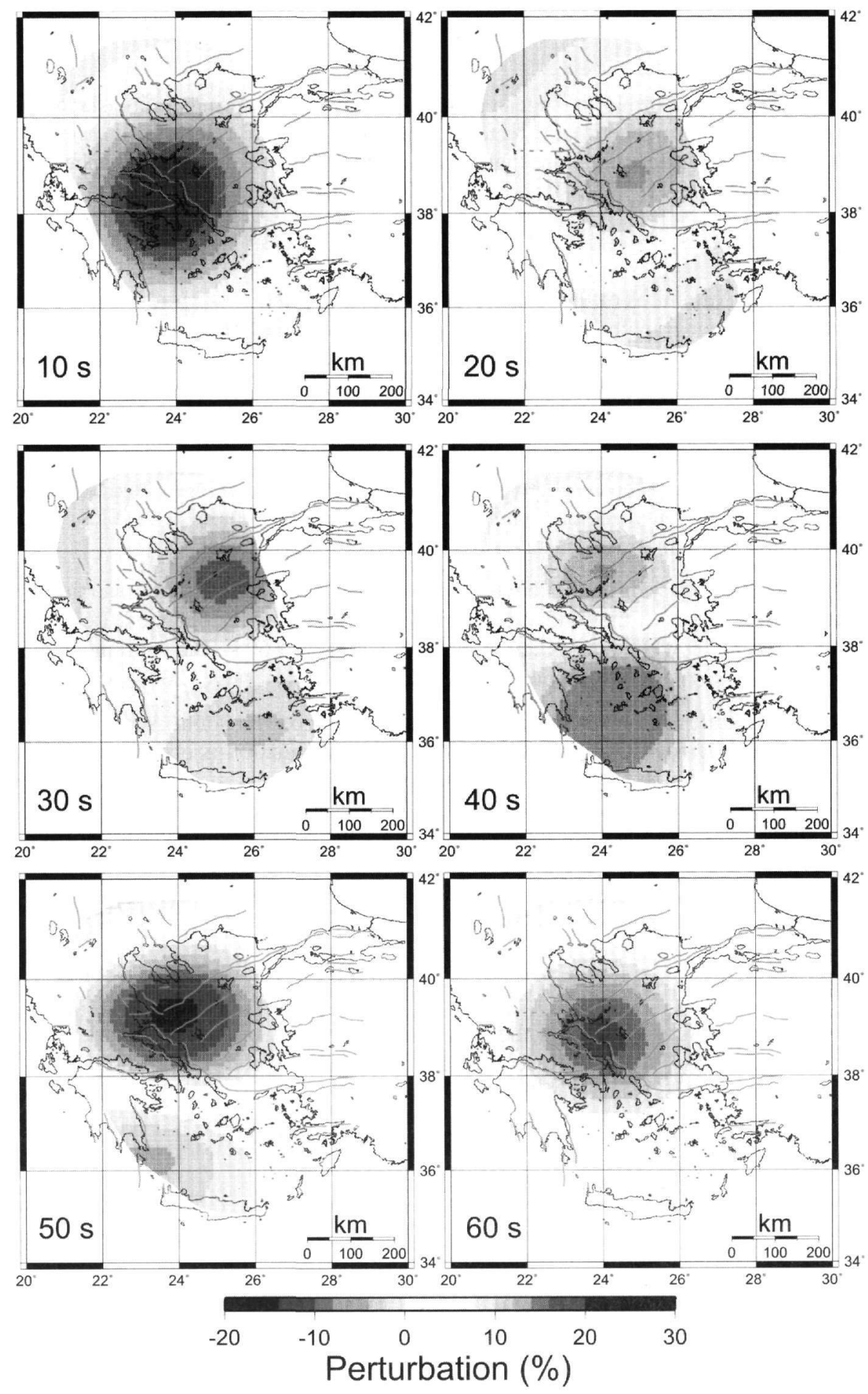

Figure 4 - Tomographic slices of the attenuation model at different periods. The attenuation perturbations are indicated with a scale in percent relative to a common reference model, derived from the average attenuation coefficient at each period. The North Anatolian Trough and other major tectonic features are superposed onto the maps 
Pliocene basalts of Western and Central Anatolia (Fytikas et al. 1984, Pe-Piper and Piper 2002, Innocenti et al. 2005).

High heat flow in the area of North Aegean signified by many hot springs in its islands, as well as the above mentioned petrogenetic and tectonic processes, may be related with a relatively thin crust $(<28 \mathrm{~km})$ or strong delamination, that is a very thin to totally absent lithospheric mantle in the area (Makris and Vees, 1977, Al-Lazki et al. 2004, Karagianni et al. 2005).

\section{Conclusions}

Although the elastic structures of the Aegean have been submitted to several studies using seismic surface waves and tomographic techniques, this is the first time that surface wave anelastic parameters are obtained for the region. Furthermore, an average joint elastic-anelastic model, representative for the Aegean lithosphere and upper mantle is derived by applying the concept of the uncoupled causal inversion.

Average $Q_{\beta}$ values at depths from 0 to $200 \mathrm{~km}$ range between $29 \pm 13$ and $23 \pm 10$ for the non-causal and uncoupled-causal inversion respectively. The observed low $Q_{\beta}$ values contrast sharply with results from stable continental regions where $Q_{\beta}$ may reach 200 or more. These low values likely indicate that fluids reside in lower crustal, as well as upper mantle depths.

Furthermore, a 3-D attenuation model beneath the Aegean, derived from the inversion of 17 path average attenuation curves of the fundamental mode Rayleigh wave is obtained. Local attenuation coefficients of the model were determined in the period range 10-60 s. The continuous regionalization approach of Montagner (1986) modified by Debayle and Sambridge (2004) was used.

One of the main features in our model is a low attenuation zone in south Aegean and east Peloponnesus likely associated with the subducted slab. High attenuation is observed beneath Central and North Aegean. This high attenuation feature extends laterally at more than $200 \mathrm{~km}$ and vertically possibly deeper than our model. This anomaly is observed to an area characterized by high extensional strain rates due to westward propagation of the NAF system within the Aegean, slab roll back and back arc basin development (McClusky et al. 2000). These observations suggest a hot or perhaps partially molten uppermost mantle and/or distributed deformation of the upper mantle beneath this region, or a combination of both.

\section{Acknowlegments}

The present study was funded through the program EPEAEK II in the framework of the project "Pythagoras - Support of University Research Groups" with 75\% from European Social Funds and $25 \%$ from National Funds", contract No. 70/3/7306.

\section{References}

Al-Lazki, A.I., Sandvol, E., Seber, D., Barazangi, M., Turkelli N., and Mohamad. R., 2004. Pn tomographic imaging of mantle lid velocity and anisotropy at the junction of the Arabian, Eurasian and African plates, Geophys. J. Int., 158, 1024-1040.

Armijo, R., Meyer, B., King, G.C.P., Rigo, A., and Papanastassiou, D., 1999. Westward propagation of the North Anatolian fault into the northern Aegean: timing and kinematics, Geology, $27,267-270$.

Bourova, E., Kassaras, I., Pedersen, H.A., Yanovskaya, T., Hatzfeld, D., and Kiratzi, A., 2005. Constraints on absolute $\mathrm{S}$ velocities beneath the Aegean Sea from surface wave analysis, Geophys. J. Int, 160, 1006-1019. 
Debayle, E., and Sambridge, M., 2004. Inversion of massive surface wave data sets: model construction and resolution assessments, J. Geophys. Res., 109, B02316, doi:10.1029/2003JB002652.

Eleftheriadis, G., Castorina, F., Soldatos, T., and Masi, U., 2003. Geochemical and Sr-Nd isotopic evidence for the genesis of the Late Cainozoic Almopia volcanic rocks (Central Macedonia, Greece), Mineralogy and Petrology, 78, 21-36.

Fytikas, M., Innocenti, F., Manetti, P., Mazzuoli, P., Reccerillo, A., and Villari, L., (eds J.E. Dixon, and A.H.F. Robertson), 1984. Tertiary to Quaternary evolution of volcanism in the Aegean region. The geological evolution of the eastern Mediterranean, Geol. Soc., London, Spec. Publ., 17, 687-699.

Hatzfeld D., Karagianni, E., Kassaras, I., Kiratzi, A., Louvari, E., Lyon-Caen, H., Makropoulos, K., Papadimitriou, P., Bock, G.. and Priestley, K., 2001. Shear wave anisotropy in the upper mantle beneath the Aegean related to internal deformation, J. Geophys. Res., 106, No12, 30737-30753.

Hatzidimitriou, P., 1993. Attenuation of coda waves in Northern Greece, Pure Appl. Geophys., $140,63-78$.

Herrmann, R.B., 1973. Some aspects of band-pass filtering of surface waves, Bull. Seism. Soc. Am., 62, 129-139.

Herrmann, R.B., (ed. R.B. HERRMANN), 1991. Surface wave inversion program, Saint Louis University, Saint Louis, MO.

Innocenti, F., Manetti, P., Reccerillo, A., and Poli, G., 1979. Inner arc volcanism in NW Aegean: geochemical and geochronological data, N. Jb. Miner., Mn., 145-158.

Innocenti F., Agostini, S., Di Vincenzo, G., Doglioni, C., Manetti, P., Savascin, M.Y., and Tonarini S., 2005. Neogene and Quaternary volcanism in Western Anatolia: Magma sources and geodynamic evolution, Marine Geology, 221, 397-421.

Jongsma, D., 1974. Heat flow in the Aegean Sea, Geophys. J. R. Astron. Soc., 37, 337- 346.

Karagianni, E.E., Papazachos, C.B, Panagiotopoulos, D.G., Suhadolc, P., Vuan, A., and Panza, G.F., 2005. Shear velocity structure in the Aegean area obtained by inversion of Rayleigh waves, Geophys. J. Int., 160, 127-143.

Kassaras, I., Makropoulos, K., Bourova, E., Pedersen, H., and Hatzfeld, D., 2005. Upper mantle structure of the Aegean derived from two-station phase velocities of fundamental mode Rayleigh waves. The South Aegean Active Volcanic Arc, Developments in Volcanology, Volume 7, Hardbound, ISBN 0-444-52046-5, Imprint ELSEVIER, 19-45.

Kovachev, S.A., Kuzin, I.P., Shoda, O.Yu., 1991. Attenuation of S waves in the lithosphere of the Sea of Crete according to OBS observation, Phys. Earth Planet. Inter., 69, 101- 111.

Makris, J. and Vees, R., 1977. Crustal structure of the Aegean Sea and the Islands of Evia and Crete, Greece, obtained by refraction seismic measurements, J. Geophys. 42, 329-341.

Makris, J., Papoulia, J., Papanikolaou, D., and Stavrakakis, G., 2001. Thinned continental crust below northern Evoikos Gulf, central Greece, detected from deep seismic soundings, Tectonophysics, 341, 225-236.

Marone, F., van der Lee, S., and Giardini, D., 2004. Three-dimensional uppermantle S-velocity model for the Eurasia-Africa plate boundary region, Geophys. J. Int., 158, 109-130.

McClusky, S., Balassanian, S., Barka, A., Demir, C., Ergintav, S., Georgiev., I., Gurkam, O., Hamburger, M., Hurst, K., Kahle, H., Kastens, K., Kekelidze, G., King, R., Kotzev, V., 
Lenk, O., Mahmoud, S., Mishin, A., Nadariya, M., Ouzounis, A., Paradissis, D., Peter, Y., Prilepin, M., Reilinger, R., Sanli, I., Seeger, H., Tealeb, A., Toksöz, M.N., and Veis, G., 2000. Global Positioning System constraints on plate motions and dynamics in the eastern Mediterranean and Caucasus, J. Geophys. Res., 105, No B3, 5695-5719.

Montagner, J., 1986. Regional three-dimensional structures using long period surface waves, Ann. Geophys., B, 4, 283-294.

Papazachos, B.C., Comninakis, P.E., 1971. Geophysical and tectonic features of the Aegean arc, $J$. Geophys. Res., 76 (35), 8517-8533.

Papazachos, C., and Nolet, G., 1997. P and S-wave velocity structure of the Hellenic area obtained by robust nonlinear inversion of travel times, J. Geoph. Res., 102, B4, 8349-8367.

Pe-Piper, G., and Piper, D.J.W., 2002. The igneous rocks of Greece, Gebruder Borntraegen, Berlin-Stuttgard, 573pp.

Polatidis, A, Kiratzi, A, Hatzidimitriou, P., and Margaris, B., 2003. Attenuation of shear-waves in the back-arc region of the Hellenic arc for frequencies from 0.6 to $16 \mathrm{~Hz}$, Tectonophysics, $367,29-40$.

Tiberi, C., Lyon-Caen, H., Hatzfeld, D., Achaeur, U., Karagianni, E., Kiratzi, A., Louvari, E., Panagiotopoulos, D., Kassaras, I., Kaviris, G., Makropoulos, K., and Papadimitriou, P., 2000. Crustal and upper mantle structure beneath the Corinth rift from a teleseismic tomography study, J. Geophys. Res., 105, 28159-28171.

Tselentis, G.-A., 1993. Depth-dependent seismic attenuation in western Greece, Tectonophysics, 225: 523- 528 . 